\title{
Patient-Centered Assessment as an Approach to Comprehensive Care in Dental Education
}

\section{Opinion}

Volume 1 Issue 1- 2021

\begin{abstract}
Author Details
Sang E Park ${ }^{*}$

Associate Dean for Dental Education, Harvard School of Dental Medicine, USA

*Corresponding author

Sang E Park, Associate Dean for Dental Education, Office of Dental Education, Harvard School of Dental Medicine 188 Longwood Ave, Boston, MA 02115, USA
\end{abstract}

Article History

Received: February 16, 2021 Accepted: February 18, 2021 Published: February 19, 2021

Keywords: Dental education, Health care providers, Clinical dentistry

\section{Introduction}

Comprehensive patient care addresses the identification of patients' health care problems as well as the delivery of dental needs. An important component of dental education involves training future practitioners to be competent oral health care providers through the delivery of comprehensive care to patients. It is also essential to assess the extent to which comprehensive care is delivered from the perspective of patients, and to confirm that continuity of care has been provided.

The traditional discipline-specific procedural requirement system is widely used as a form of clinical curriculum. It emphasizes that students meet procedural requirements through discipline-specific guidelines as part of the assessment for competency and criteria for graduation. This teaching model could unintentionally promote student or faculty-driven patient care and not patient-centered care, limiting the philosophy of comprehensive care that could potentially negatively reflect on student learning as future health care providers [1-3].

In order to shift student focus to comprehensive patient care, the clinical component of the curriculum at the Harvard School of Dental Medicine (HSDM) was redesigned to achieve patient-based comprehensive care by requiring case completion of assigned patient cases, rather than the traditional procedural numerical requirement system. The Case Completion Curriculum (CCC) as a clinical assessment model emphasizes that educational learning should be focused on achieving the treatment needs of patients, rather than on the requirements for students. Patient cases are assigned to one of six categories based on complexity defined by Case Types, and student graduation requirements are based on a threshold number of completed cases in each category outlined in the Case Selection Criteria [4-6].

\section{Reflections and Lessons Learned}

The intent of changing the clinical assessment model to a patientbased comprehensive care system was to improve both patient care and student learning in the student teaching practice. Upon evaluation of initial results, careful monitoring of patient cases and close student mentoring in patient management were considered critical to the success of the new clinical curriculum. Method of assessment could play an important role in the delivery of patient care in the student teaching practice. A patient-based comprehensive care environment required a purposeful effort to instill a sense of commitment and responsibility for patient care, and to help students learn the importance of empathic and compassionate patient management.

\section{Conclusion}

Dental education should reach beyond clinical instruction and should guide students to develop a strong professional identity at an early stage of their clinical dentistry experience. Our retrospective data and student perspective indicate that the redesigned clinical component of the curriculum could contribute to achieving a patient-based comprehensive care environment, and the Case Completion clinical curriculum could have a positive impact on student learning by prioritizing the comprehensive management of the patient.

\section{References}

1. Vining RV (1984) Comprehensive care: objectives, management, and financial impact. J Dent Educ 48(1): 7-10.

2. Formicola AJ (1991) The dental curriculum: the interplay of pragmatic necessities, national needs, and educational philosophies in shaping the future. J Dent Educ 55(6): 358-364. 
3. Field MJ (1995) Dental education at the crossroads: chal $\neg$ lenges and change. An Institute of Medicine Report. National Academy Press, Washington, DC, USA.

4. Park SE, Timothe P, Nalliah R, Karimbux N, Howell TH (2011) Implementing a Case Completion Curriculum: Challenges and Rewards. Journal of Dental Education 75(11): 1411-1416.
5. Park SE, Susarla H, Nalliah R, Timothe P, Howell TH, et al. (2012) Does a Case Completion Curriculum Influence Student Clinical Productivity? Journal of Dental Education 76(5): 602-608.

6. Park SE, Howell TH (2015) Patient-centered approaches to clinical education: A five-year reflection. J Dent Educ 79(5): 523-529. 